\title{
Erratum: "Effect of magnetite particle size on adsorption and desorption of arsenite and arsenate" [J. Mater. Res. 20, 3255 (2005)]
}

S. Yean and L. Cong

Department of Civil and Environmental Engineering, Rice University, Houston, Texas 77005

C.T. Yavuz, J.T. Mayo, W.W. Yu, and J.C. Falkner

Department of Chemistry, Rice University, Houston, Texas 77005

A.T. Kan ${ }^{\text {a) }}$

Department of Civil and Environmental Engineering, Rice University, Houston, Texas 77005

V.L. Colvin

Department of Chemistry, Rice University, Houston, Texas 77005

M.B. Tomson

Department of Civil and Environmental Engineering, Rice University, Houston, Texas 77005

(Received 11 April 2006; accepted 25 April 2006)

The purpose of this erratum is to correct the omission of a coauthor, Joshua C. Falkner, Department of Chemistry, Rice University, Houston, Texas.

\footnotetext{
a) Address all correspondence to this author.

e-mail: atk@ rice.edu

DOI: $10.1557 / J M R .2005 .0403 \mathrm{e}$ 